\title{
Autosomal Dominant Hypoparathyroidism
}

National Cancer Institute

\section{Source}

National Cancer Institute. Autosomal Dominant Hypoparathyroidism. NCI Thesaurus.

Code C129730.

Hypoparathyroidism associated with heterozygous mutation(s) in the PTH gene, which encodes parathyroid hormone, or in the GCM2 gene, which encodes chorion-specific transcription factor GCMb. 